Fixed Point Theory, 20(2019), No. 2, 541-558

DOI: $10.24193 /$ fpt-ro.2019.2.35

http://www.math.ubbcluj.ro/ ${ }_{\text {nodeacj/sfptcj.html }}$

\title{
FIXED POINT THEOREMS INVOLVING 1-SET-WEAKLY CONTRACTIVE OPERATORS IN WC-BANACH ALGEBRAS
}

\author{
BILEL KRICHEN*, BILEL MEFTEH** AND DONAL O'REGAN*** \\ *Department of Mathematics, Faculty of Sciences of Sfax \\ University of Sfax, Sfax Tunisia \\ E-mail: krichen_bilel@yahoo.fr \\ **Department of Mathematics, Faculty of Sciences of Sfax \\ University of Sfax, Sfax Tunisia \\ E-mail: bilel.mefteh@gmail.com \\ *** School of Mathematics, National University of Ireland \\ Galway, Ireland \\ E-mail: donal.oregan@nuigalway.ie
}

\begin{abstract}
In this paper, we establish some fixed point theorems for the sum and the product of nonlinear weakly sequentially continuous operators acting on a WC-Banach algebra and involving 1-set-weakly contractive maps. The obtained results are applied to a nonlinear functional integral equation in a suitable Banach algebra. Our results are extensions of several earlier results.

Key Words and Phrases: WC-Banach algebra, fixed point theorems, weak topology, measure of weak noncompactness, 1-set-weakly contractive.

2010 Mathematics Subject Classification: 47A10, 47A55, 47A53, 47H10.
\end{abstract}

\section{REFERENCES}

[1] R.P. Agarwal, N. Hussain, M.A. Taoudi, Fixed point theorems in ordered Banach spaces and applications to nonlinear integral equations, Abstr. Appl. Anal., (2012), Art. ID 245872, 15 pp.

[2] J. Appell, E. De Pascale, Su alcuni parametri connessi con la misura di non compattezza di Haussdorff in spazi di funzioni misurabili, Boll. Unione Mat. Ital. Ser. B, 6(1984), No. 3, 497515 .

[3] O. Arino, S. Gautier, J.P. Penot, A fixed point theorem for sequentially continuous mappings with applications to ordinary differential equations, Funkcial. Ekvac., 27(1984), 273-279.

[4] J. Banas, M. Lecko, Fixed points of the product of operators in Banach algebras, Panamer. Math. J., 12(2002), 101-109.

[5] J. Banas, L. Olszowy, On a class of measures of non-compactness in Banach algebras and their application to nonlinear integral equations, Z. Anal. Anwend., 28(2009), 475-498.

[6] J. Banas, M.A. Taoudi, Fixed points and solutions of operator equations for the weak topology in Banach algebras, Taiwanese J. Math., 18(2014), 871-893.

[7] A. Ben Amar, S. Chouayekh, A. Jeribi, New fixed point theorems in Banach algebras under weak topology features and applications to nonlinear integral equations, J. Funct. Anal., 259(2010), 2215-2237. 
[8] A. Ben Amar, S. Chouayekh, A. Jeribi, Fixed point theory in a new class of Banach algebras and application, Afrika Math., 24(2013), 705-724.

[9] A. Ben Amar, M. Mnif, Leray-Schauder alternatives for weakly sequentially continuous mappings and application to transport equation, Math. Methods Appl. Sci., 33(2010), 80-90.

[10] M. Benjemaa, B. Krichen, M. Meslameni, Fixed point theory in fluid mechanics: an application to the stationary Navier-Stokes problem, J. Pseudo-Differ. Oper. Appl., 8(2017), 141-146.

[11] D.W. Boyd, J.S. Wong, On nonlinear contractions, Proc. Amer. Math. Soc., 20(1969), 458-464.

[12] J. Caballero, B. Lopez, K. Sadarangani, Existence of non decreasing and continuous solutions of an integral equation with linear modification of the argument, Acta Math. Sin. Engl. Ser., 23(2007), 1719-1728.

[13] F.S. De Blasi, On a property of the unit sphere in Banach spaces, Bull. Math. Soc. Sci. Math. Roumanie, 21(1977), 259-262.

[14] B.C. Dhage, On some variants of Schauder's fixed point principle and applications to nonlinear integral equations, J. Math. Phys. Sci., 25(1998), 603-611.

[15] B.C. Dhage, A fixed point theorem in Banach algebras involving three operators with applications, Kyungpook Math. J., 44(2004), 145-155.

[16] B.C. Dhage, On a fixed point theorem in Banach algebras with applications, Appl. Math. Lett., 18(2005), 273-280.

[17] I. Dobrakov, On representation of linear operators on $C_{0}(T, X)$, Czechoslovak Math. J., 21(96)(1971), 13-30.

[18] J. Garcia-Falset, K. Latrach, Krasnoselskii-type fixed-point theorems for weakly sequentially continuous mappings, Bull. Lond. Math. Soc., 44(2012), 25-38.

[19] M.S. Gowda, G. Isac, Operators of class $(S)_{+}^{1}$, Altman's condition and the complementarity problem, J. Fac. Sci. Univ. Tokyo, Sect. IA, Math., 40(1993), 1-16.

[20] A. Jeribi, B. Krichen, Nonlinear Functional Analysis in Banach Spaces and Banach Algebras: Fixed Point Theory under Weak Topology for Nonlinear Operators and Block Operator Matrices with Applications, Monographs and Research Notes in Mathematics, CRC Press Taylor and Francis, 2015.

[21] A. Jeribi, B. Krichen, B. Mefteh, Existence of solutions of a two-dimensional boundary value problem for a system of nonlinear equations arising in growing cell populations, J. Biol. Dyn., $\mathbf{7}(2013), 218-232$.

[22] A. Jeribi, B. Krichen, B. Mefteh, Existence of solutions of a nonlinear Hammerstein integral equation, Numer. Funct. Anal. Optim., 35(2014), 1328-1339.

[23] A. Jeribi, B. Krichen, B. Mefteh, Fixed point theory in WC-Banach algebras, Turk. J. Math., 40 (2016), 283-291.

[24] M.A. Krasnosel'skii, Some problems of nonlinear analysis, Amer. Math. Soc. Trans. Ser. 2, 10(1958), 345-409.

[25] R.W. Legget, On certain nonlinear integral equations, J. Math. Anal. Appl., 57(1977), 462-468.

[26] R.E. Megginson, An Introduction to Banach Space Theory, Graduate Texts in Mathematics, Springer Verlag, 1988.

[27] D. O'Regan, Fixed point theory for weakly sequentially continuous mappings, Math. Comput. Modelling, 27(1998), 1-14.

[28] D.R. Smart, Fixed Point Theorems, Cambridge University Press, Cambridge, 1980.

[29] I.I. Vrabie, $C_{0}$-Semigroups and Applications, Elsevier, New York, 2003.

Received: March 1st, 2017; Accepted: January 11, 2018. 
